\title{
Respiratory Health and Nutritional Strategy for Competitive Swimmers 游泳選手其呼吸系統健康問題與營養策略之應用探討
}

\author{
Shu-Lin LEE \\ Department of Health Food, Chung Chou University of Science and \\ Technology, Changhua County, TAIWAN
}

Yi-Fang LEE

Department of Dietetics, Cathay Healthcare Management,

Taipei country, TAIWAN

李淑玲

台灣中州科技大學保健食品系

李宜芳

台灣國泰健康管理營養科

\begin{abstract}
There is growing interest in the potentially harmful effects in swimming pools, and the potential for swimming-related health hazards, which is gaining importance in competitive swimmers. This review was focused to discuss the following topics: (1) prevalence of respiratory difficulties in swimmers; (2) the possible factors and mechanisms which lead to the development of airway disorders in elite swimmers; (3) diet and nutrient supplementation for the management and prevention of airway problems. Summaries were concluded in this review according to the current knowledge of the respiratory problems in swimmers: (1) a high prevalence of respiratory symptoms and respiratory diseases in the elite swimmer population; (2) the potentially harmful effects in airway epithelial damage and lung permeability may caused by exposure in cold air, chlorinated products in swimming pools, and high intensity training in swimmers. (3) Observational studies have reported associations between airway symptoms and nutritional intervention (i.e. polyunsaturated fatty acid, dietary antioxidants, and vitamin D), which may have application for promoting health and sports performance for swimmers.
\end{abstract}

Key words: athletes, airway hyperresponsiveness, inflammation, nutrient supplementation.

\section{摘 要}

運動選手(如游泳選手)發生呼吸系統疾病問題逐漸受到重視, 本篇綜評旨在討論下列課題：(1)選手發生呼吸道疾病之發生 率; (2)發生呼吸疾病之可能原因及機轉; (3)飲食與營養補充對減低呼吸疾病症狀之探討。統整相關文獻後, 獲以下結語：(1)游泳 選手發生呼吸道疾病之情形高於其他運動者(如：冬季運動項目、短跑與長跑等); (2)長期處於含氯物質及其氯產物環境, 對吸呼 道䵑膜及肺組織將有所傷, 而冷空氣環境及高強度訓練模式, 亦是增加游泳選手發生呼吸道不適症狀的影響因素; (3)多元不飽和 脂肪酸、抗氧化物質及維生素 $\mathrm{D}$ 等營養素, 在減低呼吸疾病臨床研究上證實有改善效益, 對於呼吸道疾病發生率較高的游泳選手 而言, 應是不錯的飲食及營養補充介入不錯的選擇。

關鍵字：運動選手、呼吸道過度反應、發炎、營養補充 


\section{Introduction}

Swimming is a preferred physical activity for elderly, individual with arthritis, obese individuals, and cardiovascular disease patients to improve their aerobic fitness and metabolic capacity (Storms, 2003; Nualnim et al., 2012; Tanaka, 2009). Although regular swimming is considered to be an effective tool for promoting a person's overall health, recent data suggest that it may have potentially negative effects on respiratory system, particularly in competitive swimmers (Helenius et al., 2002; Pedersen, Lund, Barnes, Kharitonov, \& Backer, 2008). The prevalence of upper and lower respiratory diseases such as atopy, rhinitis, airway hyperresponsiveness (AHR), and asthma is higher in elite swimmers than the general public (Bougault, Turmel, Levesque, \& Boulet, 2009; Helenius, Rytila, et al., 1998). Previous studies have investigated some factors that may induce respiratory inflammation and allergies in swimmers (Helenius, Rytila, et al., 1998; Helenius, Tikkanen, Sarna, \& Haahtela, 1998). The research suggests that these issues may be related to airway epithelial damage and increased nasal and lung permeability caused by exposure to chlorine in swimming pools. The effects of chronic lung exposure to swimming pool, disinfected with chlorine and its byproducts, have spawned an interest these factors in the recent years (Ferrari et al., 2011; Jacobs et al., 2007). In addition, exercise training load and cold-air exposure is also considered as important factors on airway healthy for swimmers, especially in upper respiratory tract infection (URTI) incidence (Gleeson, Bishop, Oliveira, \& Tauler, 2013). Currently, specific interests in the anti-inflammatory or anti-allergy effects of polyunsaturated fatty acid (PUFA) and antioxidant compositions have led to several recent evaluations of supplements in athletes. A daily diet high in n-6 PUFA was found to be associated with an increased risk of allergic diseases, whereas n-3 PUFAs and dietary antioxidants had a protective effect. Therefore, the aim of the present review will discuss respiratory health in competitive swimmers. After review of the prevalence of respiratory symptoms and airway disorders among elite swimmers, this article will discuss the possible factors and mechanisms which lead to the development of airway disorders in elite swimmers. Furthermore, the effects of airway disorders on exercise performance and the medications for swimmers who have airway disease will also be investigated in the article. Finally, this article will also discuss studies of diet and nutrient supplementation for the management and prevention of airway problems in swimmers.

\section{Prevalence of Respiratory Difficulties in Swimmers}

The upper respiratory system includes the nose, mouth, sinuses and throat. The lower respiratory system refers to the bronchial tubes and lungs. The primary upper respiratory symptoms reported are sneezing, itching, rhinorrhoea, nasal obstruction and symptoms associated with sinusitis (Langdeau \& Boulet, 2001). However, the symptoms of a lower respiratory infection are usually more severe than those of upper respiratory illnesses and may include symptoms such as the shortness of breath or rapid breathing, wheezing, and sometimes fatal respiratory failure in clinical anamnesis (Helenius, Rytila, et al., 1998). The prevalence of upper and lower airway respiratory symptoms and respiratory diseases such as rhinitis, airway hyperresponsiveness, and asthma has dramatically increased in the developed world over the past decades. In addition, airway symptoms in recreational or competitive swimmers and schoolchildren attending swimming pools have also significantly increased (Helenius \& Haahtela, 2000; Helenius, Tikkanen, et al., 1998).

Upper airway symptoms and seasonal allergic rhinitis may impair athletes' performance and quality of life (QOL) (Langdeau \& Boulet, 2001). Nasal congestion, rhinorrhoea, sneezing and nasal itching are reported by up to $74 \%$ of competitive elite swimmers (Bougault, Turmel, \& Boulet, 2010b; Gelardi et al., 2012; Zwick, Popp, Budik, Wanke, \& Rauscher, 1990). Furthermore, studies have reported that nasal symptoms may be due to an acute viral infection or a post-infectious state during the high training level seasons (Pyne et al., 2001).

Airway hyperresponsiveness (AHR) is a respiratory symptom related to nonsensitising physical stimuli such as cold air and exercise, chemical substances such as methacholine and histamine, or sensitizing agents such as allergens, in sensitized individuals (Yan, Salome, \& Woolcock, 1983). AHR is recognized to be of higher prevalence in swimmer and winter sport athletes. Studies in competitive swimmers found the prevalence of AHR ranging from $36 \%$ to $79 \%$; this was significantly higher than controls (4\%) (Helenius, Rytila, et al., 1998; Helenius, Tikkanen, et al., 1998). Zwick et al. (1990) found 9 of 14 competitive swimmers to be diagnosed with AHR in a metacholine test (Zwick et al., 1990). Bougault et al. (2010) found that $60 \%$ of swimmers, $29 \%$ of winter sport athletes, and $17 \%$ of controls had AHR or exerciseinduced bronchoconstriction (EIB), and they could be 
allowed to use certain types of asthma medication (Bougault, Turmel, \& Boulet, 2010a). Therefore, those studies indicated that a high prevalence of symptomatic and asymptomatic AHR and/or EIB occur in the elite swimmer population, whereas winter sport athletes often report exercise-induced cough but with a prevalence of AHR and/or EIB similar to nonathletic controls.

Asthma is characterized by chronic allergic airway inflammation with remodeling, cell infiltration in lung, and airway hyperresponsiveness to stimulations. The prevalence of asthma has increased over the last 2 decades, and is also commonly found in sporting events, such as swimming, cycling, or long-distance running. Potts (1994) reported that $13.4 \%$ of 738 swimmers have asthma (Potts, 1994). Larsson et al. (1993) observed increased bronchial responsiveness in $38 \%$ of 42 elite cross-country skiers, and an additional $21 \%$ of the skiers had asthma diagnosed by a physician. They also found that $18 \%$ of the speed and power athletes (e.g. sprinters), $8 \%$ of the long-distance runners, and $36 \%$ of the swimmers had increased bronchial responsiveness, and 12\%, 7\%, and $26 \%$ of them had asthma at the current time, respectively (Larsson et al., 1993). Therefore, based on the reported data, respiratory symptoms in swimmers are a more common problem than other types of sports.

\section{Factors Possibly Contributing to Respiratory Difficulties in Swimmers}

Not only are respiratory symptoms frequently reported by elite swimmers, but they are also reported by swimming pool workers and children who regularly attending swimming pools with their school (Thickett, Mccoach, Gerber, Sadhra, \& Burge, 2002; Uyan, Carraro, Piacentini, \& Baraldi, 2009). The symptoms may be related to airway epithelial damage and increased bronchial epithelial shedding and lung permeability caused by exposure to environments that are high in chlorine, such as swimming pools. However, recent research has also found that airway inflammation may be triggered by high level repeated exercise loading. Swimming pool water needs to be disinfected regularly. The most frequently used disinfection method is chlorination, which removes pathogens with chlorine or its derivatives, but the free chlorine reacts with organic matter (e.g. urine, saliva, and sweat) and forms a mixture of potentially harmful disinfectant by-products, including chloramines (Who, 2006; Zarzoso, Llana, \& Pérez-Soriano, 2010). Chloramines contain the inorganic compounds monochloramine $\left(\mathrm{NH}_{2} \mathrm{Cl}\right)$, dichloramine $(\mathrm{NHCl} 2)$ and trichloramine $(\mathrm{NCl} 3)$. The chlorination by-products in these environments have potentially harmful effects on allergic and respiratory health in humans (Glauner, Waldmann, Frimmel, \& Zwiener, 2005; Kohlhammer, Doring, Schafer, Wichmann, \& Heinrich, 2006). Recent studies show that chloramines may cause respiratory health problems in swimming pool workers, pool visitors (particularly children), and also in competitive swimmers (Jacobs et al., 2007; Thickett et al., 2002; Uyan et al., 2009). In Ferrari et al. study, they investigated the potential correlation between attendance at chlorinated indoor pools and the onset of asthma in 1136 adult leisure swimmers. The results showed that the prevalence of asthma was higher in swimmers characterized by a higher cumulative pool attendance (23/514, 4.5\%) than in swimmers who were attending indoor pools less frequently $(2 / 508,0.4 \%)$. Therefore, this study illustrated that attendance at chlorinated indoor pools may constitute a risk factor for developing asthma in leisure adult swimmers (Ferrari et al., 2011). However, there is a notable problem in that swimmers training for at least 30 hours per week are 20 times more exposed to chlorine compounds than lifeguards and about 100 times more than recreational swimmers (Helenius, Tikkanen, et al., 1998). Bougault et al. (2012) analyzed the clinical data from twenty-three competitive swimmers, 10 age-matched mild-asthmatic, and 10 healthy non-allergic subjects. The results showed that long-term swimming training in indoor chlorinated swimming pools was associated with airway changes similar to those seen in mild asthma subjects (Bougault et al., 2012). Experimental evidence also suggests that exposure to chloramines compounds in indoor swimming pools cause epithelial hyper-permeability and damage, which may facilitate mucosal penetration by allergens and induce allergic sensitization (Bernard, 2007). Asthma symptoms, airway obstruction and increased bronchial responsiveness may arise as a result of repeated exposure to chlorine gas (Bernard, 2007). In these cases, histological analysis of the bronchial mucosa has shown a thickened basement membrane, eosinophilic inflammation, and a relative lack of T-lymphocytes (Pyne et al., 2001).

Increased airway afflictions in swimmers seem to be partly related to the training duration and intensity (Gleeson et al., 2013). High-level sport training induced airway changes via high ventilator demand sustained during repeated strenuous period (Langdeau \& Boulet, 2001). Since swimmers spend many hours per week training in cold air or a chlorinated environment, they 
are particularly affected by respiratory symptoms and airway hyperresponsiveness (Lakier Smith, 2003). Numerous studies have found an inverse relationship between training workloads and immune function (Helenius, Rytila, et al., 1998; Winsley \& Matos, 2011). In agreement with this, previous studies reported that increased bronchial inflammation and peripheral leukocytosis expression in athletes who have symptoms of overtraining (Lakier Smith, 2003; Wilson, Zaldivar, Schwindt, Wang-Rodriguez, \& Cooper, 2009). However, high-level competition also seems to exacerbate at least some components of the allergic immune response, such as airway hyper responsiveness and airway inflammation, especially in allergic athletes (Gleeson et al., 2002; Seyfried, Tobin, Brown, \& Ness, 1985). Therefore, excessive amounts of prolong and highintensity exercise impair the immune system as well as mucosal defense which contribute to an increased risk for respiratory tract illness in swimmers (Pyne et al., 2001)

\section{Mechanisms of Airway Issues in Swimmers Upper respiratory tract infections (URIs)}

Studies have shown that the risk of URI is increased in people who are under heavy physical stress in physically active populations, including swimmers, possibly because of changes in the immune function caused by heavy exertion (Gleeson, 2007). The concept of a U-shaped response has now been extended to cover the effects of physical activity upon a variety of clinical disturbances of immune function, such as high numbers of neutrophil and low numbers of lymphocytes in blood counts, impaired macrophages phagocytosis and neutrophilic function, decreased oxidative burst activity, natural killer cell cytolytic activity, and mucosal immunoglobulin levels (Main et al., 2010; Nieman, 1997). Researchers have also observed that intense training may also enhance the release of pro-inflammatory cytokines such as tumor necrosis factor alfa (TNF- $\alpha$ ), interleukin-1b (IL-1b) and IL-6, followed closely by anti-inflammatory cytokines, such as IL-10 and interleukin-1 receptor antagonist (IL-1ra) (Ostrowski, Rohde, Asp, Schjerling, \& Pedersen, 1999). Those cytokines are likely to play an important role in modulating post-exercise changes in immune function that aggravate the risk of infection or the appearance of inflammatory symptoms, and also associate with significant persisting fatigue and poor performance (Purvis, Gonsalves, \& Deuster, 2010).

\section{Airway Hyperresponsiveness and Asthma}

The idea that long term repeated exposure to chlorine compound derivatives cause airway inflammation in elite swimmers is now generally. Increasing evidence suggests that airway inflammation is responsible for all of the associated features of asthma, including the increase airway responsiveness, airway edema, hypersecretion of mucus, and inflammatory cell infiltration. Furthermore, the inflammation may represent a multi-factorial aggression, in which both allergic and irritant mechanisms play a role. The experimental evidence supports the concept that non-inflammatory cells, including airway epithelial cells and neural cells, especially those of peptidergic nerves, contribute to the inflammation. In addition, newly identified cells of the innate immune system and pathways linked to asthma have been described in a review paper by Kim et al. (Kim, Dekruyff, \& Umetsu, 2010). The researchers determined that innate immune mechanisms, involving a host of newly identified cytokines and cell types, can also induce AHR. A number of inflammatory cells in the pathway are mainly eosinophils, mast cells, neutrophils, macrophages, and basophils. In addition, lymphocytes, such as T-helper 2 cell (TH2) and thymic stromal lymphopoietin (TSLP), are implicated. When specific antigens stimulated the antigen-presenting cells (APCs) or dendritic cells (DCs), lymphocyte activation considered crucial for the initiation and perpetuation of the inflammatory responses (Bhakta \& Woodruff, 2011). Many inflammatory mediators have been identified in airway hyper responsiveness and asthma. Such mediators are cytokines, such as IL-3, IL-4, IL5, and IL-13 secreted by $\mathrm{TH} 2$ cells. They are important mediators of asthmatic and allergic inflammation that is characterized by elevated immunoglobulin E (IgE), mast-cell degranulation, and eosinophilic inflammation. Furthermore, other inflammatory mediators that probably playing a role, particularly in acute bronchoconstriction, include arachidonic acid metabolic, such as leukotrienes and prostaglandins, platelet-activating factor (PAF), neuropeptides, reactive oxygen species, kinins, histamine, and adenosine (Nieman, 1997). 


\section{Medication for Respiratory Issues}

Medications used in the treatment of respiratory disorders (such as asthma medications) in competitive athletes are regulated by the international Olympic committee edictal commission (IOC-MC) and the World Anti-Doping Agency (Wolfarth, Wuestenfeld, \& Kindermann, 2010). The most commonly used drug is inhaled $\beta 2$-adrenoceptor agonists ( $\beta 2$-agonists), which contain salbutamol, terbutaline, bambuterol, fenoterol, formoterol, salmeterol, and tulobuterol. However, the potential ergogenic effects of $\beta 2$-agonists medication in athletes have been controversially discussed for decades (Carlsen et al., 2001; Wolfarth et al., 2010). Therefore, $\beta 2$-agonists are prohibited according to the "Prohibited List of the World Anti-Doping Agency", and the IOC restricts the use of inhaled $\beta 2$-agonists and requires documentation for their use. In 2010 WADA allow salbutamol and salmeterol by inhalation requiring a so called "declaration of use" (Wolfarth et al., 2010).

As mild eosinophilic airway inflammation affects athletes with bronchial symptoms, it has been suggested that treatment of asthmatic symptoms should be started with inhaled corticosteroids. Orally active leukotriene antagonists are recent developments in the treatment of asthma, and prevent exacerbations as effectively as longacting $\beta 2$-agonists (Ducharme, 2011).

\section{Dietary Nutrition and Respiratory Issues}

The research on the relationship between nutrition and airway diseases has been focused mainly on the role of dietary nutrients as ergogenic aids (Grimble, 2001). Currently, nutrients are discussed in three groups: polyunsaturated fatty acid (PUFA), antioxidants (vitamin A, C, E, selenium, and antioxidant-rich foods or components), and vitamin D. Scholars have hypothesized that decreasing antioxidant, increased n-6 PUFA (such as margarine, vegetable oil), and decreased n-3 PUFA (such as oily fish) intakes have contributed to the recent increases in asthma and atopic disease (Allan \& Devereux, 2011; Devereux \& Seaton, 2005). In addition, recent studies have also found that vitamin D consumption had a relationship with respiratory infections and lung function (Berry, Hesketh, Power, \& Hypponen, 2011).

\section{PUFA}

The most common dietary PUFAs are linoleic acid (n-6) and $\alpha$-linolenic acid (n-3), both of which can be converted to longer-chain PUFAs by a single desaturation and elongation enzyme pathway. Associations have been reported between respiratory inflammation and dietary intake and blood concentrations of individual PUFAs (Sala-Vila, Miles, \& Calder, 2008). In a review paper by Mickleborough et al. (2008), the researchers integrated the metabolism of $n-3$ and $n-6$ fatty acids after ingestion via the 5-lipoxygenase and cyclooxygenase enzymatic (COX) pathways and investigated the subsequent effects on inflammatory activity and bronchoconstriction (Mickleborough, Lindley, \& Montgomery, 2008). The review concluded that higher amount of $\mathrm{n}-6$ PUFA ingestion is associated with allergy and asthma. This is because linoleic acid of PUFA is converted into arachidonic acid that can be metabolized by lipoxygenase and cyclooxygenase enzymes ultimately to produce 2-series prostaglandins, thromboxanes, and 4-series leukotrienes, lipoxins that are of particular pertinence to asthma and allergy disease (GonzalezPeriz \& Claria, 2007). Four-series leukotrienes have proinflammatory activity, and the 2-series prostaglandin E2 (PGE2) is known to have immunomodulatory properties, promoting the TH2 phenotype associated with asthma and atopic disease (Phipps, Stein, \& Roper, 1991). However, dietary intake of n-3 $\alpha$-linolenic acids, such as eicosapentaenoic acid (EPA) and docosahexaenoic acid (DHA) in fish oils, would reduce arachidonic acid and PGE2 production thus serving as an anti-inflammatory substrate, because $\alpha$-linolenic acid competitively inhibits linoleic acid metabolism by the single enzyme cascade, and EPADHA reduces COX-2 gene expression and inhibits COX-2 activity to reduce prostaglandin generation (Mickleborough et al., 2008; Obata, Nagakura, Masaki, Maekawa, \& Yamashita, 1999).

Most intervention studies of n-3 PUFA supplementation in established asthma and respiratory inflammation have used fish oil capsules with the conclusion that n-3 PUFA supplementation shown to reduce exercise induced airway narrowing in elite athletes and individuals with mild-to-moderate asthma (Barros et al., 2011; Fasano, Serini, Piccioni, Innocenti, \& Calviello, 2010). For example, Arm and colleagues investigated the effects of $3.2 \mathrm{~g}$ EPA and $2.2 \mathrm{~g}$ DHA per day versus a placebo for 10 weeks in asthmatic subjects. They found that the total leukotriene B (LTB) production in 
the fish oil-supplemented group was inhibited by 50\% in stimulated neutrophils while no change was seen in the placebo group (Arm et al., 1988). In another study, Mickleborough et al. examined the effect of fish oil supplementation (3.2 g EPA and $2.2 \mathrm{~g}$ DHA intake for 3 weeks) in 10 elite athletes who experienced EIB. The results strongly suggested that dietary supplementation with fish oil has a markedly protective effect in suppressing EIB in elite athletes, and this may be attributed to their anti-inflammatory properties(Mickleborough, Murray, Ionescu, \& Lindley, 2003).

\section{Antioxidants and Vitamins}

Recent studies also show evidence that intense exercise can produce an imbalance between the free radicals and reactive oxygen species produced by the antioxidant defense system (Radak, Chung, Koltai, Taylor, \& Goto, 2008). Studies in experimental models also reported that oxidants induce many features of airway hyperresponsiveness and asthma by inducing the release of proinflammatory mediators, including cytokines, chemokines, and eicosanoid metabolites. Therefore, oxidant stress also influences the inflammatory regulation (Gao et al., 2011). Many intervention studies suggested that antioxidantbased components, such as vitamin $\mathrm{C}$, vitamin $\mathrm{E}$, some carotenoids, selenium, and antioxidant-rich plant, may effectively reduce inflammation associated with oxidant stress-related challenge to the respiratory mucosa (Gao et al., 2011). A recent systematic review and meta-analysis of 40 studies relating vitamin $\mathrm{A}, \mathrm{C}$, and $\mathrm{E}$ to asthma concluded that dietary vitamin $\mathrm{A}$ and $\mathrm{C}$ intake and blood vitamin $\mathrm{C}$ levels were significantly lower in adults and children with asthma who wheeze, especially in those with severe asthma. Vitamin E intake was significantly lower in people with severe asthma.(Allen, Britton, \& LeonardiBee, 2009) In addition, the double-blind and placebocontrolled intervention trial by Constantini et al. examined the effects of vitamin C supplementation (1 $\mathrm{g} /$ day) for three months on URIs in 39 adolescent swimmers (Constantini et al., 2011). The results showed that the duration of URI episodes was $21 \%$ shorter in the vitamin C group, although the effect was not statistically significant. They also found that vitamin $\mathrm{C}$ supplementation decreased the duration and severity of respiratory infections in male swimmers, but not in females. The authors speculated that lower vitamin $\mathrm{C}$ levels in males compared with females may explain the sex differences in the supplementation effect (Grimble, 2001).
Selenium (Se) is a potent nutritional antioxidant important for various aspects of human health. Recent studies suggest that increased Se status may be exploited to modulate immune processes that drive certain immune disorders, such as lung cytokine levels or airway cellular infiltration that drive asthmatic and allergic inflammation (Hoffmann et al., 2007). Therefore, it has been hypothesized that increased intake of Se may modulate oxidative stress in various tissues including the lung, and it would certainly make sense that Se could potentially decrease asthma pathology (Norton \& Hoffmann, 2012).

Dietary polyphenols are also an important antioxidant component, and polyphenols (such as resveratrol) (Knobloch et al., 2010), green tea catechins/quercetin (Liang et al., 2011), and curcumin (Oh et al., 2011)) have been reported to increase intracellular thiol status along with induction of GSH biosynthesis (Zang et al., 2011). Such an elevation in the thiol status in turn leads to detoxification of free radicals and oxidants as well as inhibition of ongoing inflammatory responses, which prevent airway inflammation (Rahman, 2008). Therefore, the studies discussed above suggest that there are beneficial associations between airway respiratory health and dietary antioxidants.

\section{Vitamin D}

Extensive evidence shows that vitamin D insufficiency is associated with respiratory health, including the asthma, respiratory tract infection and COPD (Berry et al., 2011; Liu et al., 2013). Studies have provided evidence that vitamin D modulates cytokine profiles in animal models of autoimmune disease through limiting excessive production of proinflammatory cytokines, such as TNF$\alpha$ and IL-12, and thus leading to suppression of respiratory inflammation (Ginde, Mansbach, \& Camargo, 2009). A highly prevalence of vitamin D deficiency in the general population has been documentation, but a handful of studies investigated the prevalence on athletes (Larson-Meyer \& Willis, 2010). However, researches figured out that vitamin D status in athletes may dependent on the training time, skin color, and geographic location (Hilger et al., 2013). Measurement of serum 25-hydroxycholecalciferol [25(OH)D] concentration is the best indicator of vitamin D status (Edlich et al., 2009). Therefore, serum 25(OH) D concentration of $\geqq 32$ and preferable $\geqq 40 \mathrm{ng} / \mathrm{mL}$ is recommendation for athletes. Further research is needed to determine the effect of vitamin D status 
in competitive swimmers, who has higher prevalence of upper and lower respiratory diseases.

\section{Summary}

A high incidence of upper and lower airway respiratory symptoms have been reported in competitive swimmers. Many observational studies reported that increased n-6 PUFA, and decreased n-3 PUFA intakes may contribute to increases in asthma and atopic disease, and decreasing dietary antioxidant might influence disease pathogenesis through both reduced antioxidant and immunomodulatory mechanisms. In additionally, vitamin D insufficiency is associated with respiratory health. Therefore, athletes should pay attention the training environment and nutritional status during the training period. Further research into the respiratory health and dietary nutrition implication with competitive swimmer is required, and in particular the role of diet during the training period as well as the issue of individual susceptibility in swimmers.

\section{Reference}

Allan, K., \& Devereux, G. (2011). Diet and asthma: nutrition implications from prevention to treatment. Journal of the American Dietetic Association, 111(2), 258-268.

Allen, S., Britton, J. R., \& Leonardi-Bee, J. A. (2009). Association between antioxidant vitamins and asthma outcome measures: systematic review and metaanalysis. Thorax, 64(7), 610-619.

Arm, J. P., Horton, C. E., Mencia-Huerta, J. M., House, F., Eiser, N. M., Clark, T. J., . . . Lee, T. H. (1988). Effect of dietary supplementation with fish oil lipids on mild asthma. Thorax, 43(2), 84-92.

Barros, R., Moreira, A., Fonseca, J., Delgado, L., CastelBranco, M. G., Haahtela, T., . . . Moreira, P. (2011). Dietary intake of alpha-linolenic acid and low ratio of n-6:n-3 PUFA are associated with decreased exhaled NO and improved asthma control. British Journal of Nutrition, 106(3), 441-450.
Bernard, A. (2007). Chlorination products: emerging links with allergic diseases. Current Medicinal Chemistry, 14(16), 1771-1782.

Berry, D. J., Hesketh, K., Power, C., \& Hypponen, E. (2011). Vitamin D status has a linear association with seasonal infections and lung function in British adults. British Journal of Nutrition, 106(9), 14331440.

Bhakta, N. R., \& Woodruff, P. G. (2011). Human asthma phenotypes: from the clinic, to cytokines, and back again. Immunological Reviews, 242(1), 220-232.

Bougault, V., Loubaki, L., Joubert, P., Turmel, J., Couture, C., Laviolette, M., . . . Boulet, L. P. (2012). Airway remodeling and inflammation in competitive swimmers training in indoor chlorinated swimming pools. Journal of Allergy and Clinical Immunology, 129(2), 351-358.

Bougault, V., Turmel, J., \& Boulet, L.-P. (2010a). Bronchial challenges and respiratory symptoms in elite swimmers and winter sport athletes: Airway hyperresponsiveness in asthma: its measurement and clinical significance. Chest, $138(2$ suppl), 31S-37S.

Bougault, V., Turmel, J., \& Boulet, L. P. (2010b). Effect of intense swimming training on rhinitis in high-level competitive swimmers. Clinical and Experimental Allergy, 40(8), 1238-1246.

Bougault, V., Turmel, J., Levesque, B., \& Boulet, L. P. (2009). The respiratory health of swimmers. Sports Medicine, 39(4), 295-312.

Carlsen, K. H., Hem, E., Stensrud, T., Held, T., Herland, K., \& Mowinckel, P. (2001). Can asthma treatment in sports be doping? The effect of the rapid onset, long-acting inhaled $\beta 2$-agonist formoterol upon endurance performance in healthy well-trained athletes. Respiratory Medicine, 95(7), 571-576.

Constantini, N. W., Dubnov-Raz, G., Eyal, B. B., Berry, E. M., Cohen, A. H., \& Hemila, H. (2011). The effect of vitamin $\mathrm{C}$ on upper respiratory infections in adolescent swimmers: a randomized trial. European Journal of Pediatrics, 170(1), 59-63. 
Devereux, G., \& Seaton, A. (2005). Diet as a risk factor for atopy and asthma. Journal of Allergy and Clinical Immunology, 115(6), 1109-1117.

Ducharme, F. M. (2011). Leukotriene receptor antagonists as first line or add-on treatment for asthma. British Medical Journal, 343.

Edlich, R., Fisher, A. L., Chase, M. E., Brock, C. M., Gubler, K., \& Long, W. B., 3rd. (2009). Modern concepts in the diagnosis and treatment of vitamin D deficiency and its clinical consequences. Journal of Environmental Pathology, Toxicology and Oncology, 28(1), 1-4

Fasano, E., Serini, S., Piccioni, E., Innocenti, I., \& Calviello, G. (2010). Chemoprevention of lung pathologies by dietary n-3 polyunsaturated fatty acids. Current Medicinal Chemistry, 17(29), 3358-3376.

Ferrari, M., Schenk, K., Mantovani, W., Papadopoulou, C., Posenato, C., Ferrari, P., . . . Tardivo, S. (2011). Attendance at chlorinated indoor pools and risk of asthma in adult recreational swimmers. Journal of Science and Medicine in Sport, 14(3), 184-189.

Gao, M., Singh, A., Macri, K., Reynolds, C., Singhal, V., Biswal, S., \& Spannhake, E. W. (2011). Antioxidant components of naturally-occurring oils exhibit marked anti-inflammatory activity in epithelial cells of the human upper respiratory system. Respiratory Research, 12, 92.

Gelardi, M., Ventura, M. T., Fiorella, R., Fiorella, M. L., Russo, C., Candreva, T., . . . Passalacqua, G. (2012). Allergic and non-allergic rhinitis in swimmers: clinical and cytological aspects. British Journal of Sports Medicine, 46(1), 54-58.

Ginde, A. A., Mansbach, J. M., \& Camargo, C. A., Jr. (2009). Vitamin D, respiratory infections, and asthma. Current Allergy and Asthma Reports, 9(1), 81-87.

Glauner, T., Waldmann, P., Frimmel, F. H., \& Zwiener, C. (2005). Swimming pool water--fractionation and genotoxicological characterization of organic constituents. Water Research, 39(18), 4494-44502.
Gleeson, M. (2007). Immune function in sport and exercise. Journal of Applied Physiology, 103(2), 693699.

Gleeson, M., Bishop, N., Oliveira, M., \& Tauler, P. (2013). Influence of training load on upper respiratory tract infection incidence and antigen-stimulated cytokine production. Scandinavian Journal of Medicine \& Science in Sports, 23(4), 451-457.

Gleeson, M., Pyne, D. B., Austin, J. P., Lynn Francis, J., Clancy, R. L., McDonald, W. A., \& Fricker, P. A. (2002). Epstein-Barr virus reactivation and upper-respiratory illness in elite swimmers. Medicine and Science in Sports and Exercise, 34(3), 411-417.

Gonzalez-Periz, A., \& Claria, J. (2007). New approaches to the modulation of the cyclooxygenase- 2 and 5-lipoxygenase pathways. Current Topics in Medicinal Chemistry, 7(3), 297-309.

Grimble, R. F. (2001). Nutritional modulation of immune function. Proceedings of the Nutrition Society, 60(3), 389-397.

Helenius, I., \& Haahtela, T. (2000). Allergy and asthma in elite summer sport athletes. The Journal of Allergy and Clinical Immunology, 106(3), 444-452.

Helenius, I., Rytila, P., Sarna, S., Lumme, A., Helenius, M., Remes, V., \& Haahtela, T. (2002). Effect of continuing or finishing high-level sports on airway inflammation, bronchial hyperresponsiveness, and asthma: a 5-year prospective follow-up study of 42 highly trained swimmers. [Research Support, Non-U.S. Gov't]. Journal of Allergy and Clinical Immunology, 109(6), 962-968.

Helenius, I. J., Rytila, P., Metso, T., Haahtela, T., Venge, P., \& Tikkanen, H. O. (1998). Respiratory symptoms, bronchial responsiveness, and cellular characteristics of induced sputum in elite swimmers. Allergy, 53(4), 346-352.

Helenius, I. J., Tikkanen, H. O., Sarna, S., \& Haahtela, T. (1998). Asthma and increased bronchial responsiveness in elite athletes: Atopy and sport event as risk factors. Journal of Allergy and Clinical Immunology, 101(5), 646-652. 
Hilger, J., Friedel, A., Herr, R., Rausch, T., Roos, F., Wahl, D. A., . . . Hoffmann, K. (2013). A systematic review of vitamin D status in populations worldwide. British Journal of Nutrition, 1-23.

Hoffmann, P. R., Jourdan-Le Saux, C., Hoffmann, F. W., Chang, P. S., Bollt, O., He, Q., . . . Berry, M. J. (2007). A role for dietary selenium and selenoproteins in allergic airway inflammation. Journal of Immunology, 179(5), 3258-3267.

Jacobs, J. H., Spaan, S., van Rooy, G. B. G. J., Meliefste, C., Zaat, V. A. C., Rooyackers, J. M., \& Heederik, D. (2007). Exposure to trichloramine and respiratory symptoms in indoor swimming pool workers. European Respiratory Journal, 29(4), 690698.

Kim, H. Y., DeKruyff, R. H., \& Umetsu, D. T. (2010). The many paths to asthma: phenotype shaped by innate and adaptive immunity. Nature Immunology, 11(7), 577-584.

Knobloch, J., Sibbing, B., Jungck, D., Lin, Y., Urban, K., Stoelben, E., . . . Koch, A. (2010). Resveratrol impairs the release of steroid-resistant inflammatory cytokines from human airway smooth muscle cells in chronic obstructive pulmonary disease. The Journal of Pharmacology and Experimental Therapeutics, 335(3), 788-798.

Kohlhammer, Y., Doring, A., Schafer, T., Wichmann, H. E., \& Heinrich, J. (2006). Swimming pool attendance and hay fever rates later in life. Allergy, 61(11), 1305-1309.

Lakier Smith, L. (2003). Overtraining, excessive exercise, and altered immunity: is this a $\mathrm{T}$ helper- 1 versus $\mathrm{T}$ helper-2 lymphocyte response? Sports Medicine, 33(5), 347-364.

Langdeau, J. B., \& Boulet, L. P. (2001). Prevalence and mechanisms of development of asthma and airway hyperresponsiveness in athletes. Sports Medicine, 31(8), 601-616.
Larson-Meyer, D. E., \& Willis, K. S. (2010). Vitamin D and athletes. Current Sports Medicine Reports, 9(4), 220-226.

Larsson, K., Ohlsen, P., Larsson, L., Malmberg, P., Rydstrom, P. O., \& Ulriksen, H. (1993). High prevalence of asthma in cross country skiers. British Medical Journal, 307(6915), 1326-1329.

Liang, O. D., Kleibrink, B. E., Schuette-Nuetgen, K., Khatwa, U. U., Mfarrej, B., \& Subramaniam, M. (2011). Green tea epigallo-catechin-galleate ameliorates the development of obliterative airway disease. Experimental Lung Research, 37(7), 435-444.

Liu, X., Nelson, A., Wang, X., Farid, M., Gunji, Y., Ikari, J., . . . Rennard, S. I. (2013). Vitamin D Modulates PGE2 Synthesis and Degradation in Human Lung Fibroblasts. American journal of respiratory cell and molecular biology, [Epub ahead of print].

Main, L. C., Dawson, B., Heel, K., Grove, J. R., Landers, G. J., \& Goodman, C. (2010). Relationship between inflammatory cytokines and self-report measures of training overload. Research in Sports Medicine, 18(2), 127-139.

Mickleborough, T. D., Lindley, M. R., \& Montgomery, G. S. (2008). Effect of fish oil-derived omega-3 polyunsaturated Fatty Acid supplementation on exercise-induced bronchoconstriction and immune function in athletes. Physician and Sportsmedicine, 36(1), 11-17.

Mickleborough, T. D., Murray, R. L., Ionescu, A. A., \& Lindley, M. R. (2003). Fish oil supplementation reduces severity of exercise-induced bronchoconstriction in elite athletes. American Journal of Respiratory and Critical Care Medicine, 168(10), 1181-1189.

Nieman, D. C. (1997). Immune response to heavy exertion. Journal of Applied Physiology, 82(5), 1385-1394.

Norton, R. L., \& Hoffmann, P. R. (2012). Selenium and asthma. Molecular Aspects of Medicine, 33(1), 98-106. 
Nualnim, N., Parkhurst, K., Dhindsa, M., Tarumi, T., Vavrek, J., \& Tanaka, H. (2012). Effects of Swimming Training on Blood Pressure and Vascular Function in Adults. 50 Years of Age. American Journal of Cardiology.

Obata, T., Nagakura, T., Masaki, T., Maekawa, K., \& Yamashita, K. (1999). Eicosapentaenoic acid inhibits prostaglandin D2 generation by inhibiting cyclooxygenase-2 in cultured human mast cells. Clinical and Experimental Allergy, 29(8), 1129-1135.

Oh, S. W., Cha, J. Y., Jung, J. E., Chang, B. C., Kwon, H. J., Lee, B. R., \& Kim, D. Y. (2011). Curcumin attenuates allergic airway inflammation and hyperresponsiveness in mice through NF-kappaB inhibition. Journal of Ethnopharmacology, 136(3), 414-421.

Ostrowski, K., Rohde, T., Asp, S., Schjerling, P., \& Pedersen, B. K. (1999). Pro- and anti-inflammatory cytokine balance in strenuous exercise in humans. Journal of Ahysiology, 515 ( Pt 1), 287-291.

Pedersen, L., Lund, T. K., Barnes, P. J., Kharitonov, S. A., \& Backer, V. (2008). Airway responsiveness and inflammation in adolescent elite swimmers. J Allergy Clin Immunol, 122(2), 322-327.

Phipps, R. P., Stein, S. H., \& Roper, R. L. (1991). A new view of prostaglandin $E$ regulation of the immune response. Immunology Today, 12(10), 349-352.

Potts, J. (1994). Adverse respiratory health effects of competitive swimming: The prevalence of symptoms, illness, and bronchial responsiveness to metacholine and exercise. Vancouver (BC): University of British Columbia.

Purvis, D., Gonsalves, S., \& Deuster, P. A. (2010). Physiological and psychological fatigue in extreme conditions: overtraining and elite athletes. Journal of Injury, Function, and Rehabilitation, 2(5), 442-450.

Pyne, D. B., McDonald, W. A., Gleeson, M., Flanagan, A., Clancy, R. L., \& Fricker, P. A. (2001). Mucosal immunity, respiratory illness, and competitive performance in elite swimmers. [Article]. Medicine and Science in Sports and Exercise, 33(3), 348-353.
Radak, Z., Chung, H. Y., Koltai, E., Taylor, A. W., \& Goto, S. (2008). Exercise, oxidative stress and hormesis. Ageing Research Reviews, 7(1), 34-42.

Rahman, I. (2008). Review: Antioxidant therapeutic advances in COPD. Therapeutic Advances in Respiratory Disease, 2(6), 351-374.

Sala-Vila, A., Miles, E. A., \& Calder, P. C. (2008). Fatty acid composition abnormalities in atopic disease: Evidence explored and role in the disease process examined. Clinical and Experimental Allergy, 38(9), 1432-1450.

Seyfried, P. L., Tobin, R. S., Brown, N. E., \& Ness, P. F. (1985). A prospective study of swimming-related illness. I. Swimming-associated health risk. American Journal of Public Health, 75(9), 1068-1070.

Storms, W. W. (2003). Review of exercise-induced asthma. Medicine \& Science in Sports \& Exercise, 35(9), 1464-1470

Tanaka, H. (2009). Swimming exercise: impact of aquatic exercise on cardiovascular health. Sports Medicine, 39(5), 377-387.

Thickett, K. M., McCoach, J. S., Gerber, J. M., Sadhra, S., \& Burge, P. S. (2002). Occupational asthma caused by chloramines in indoor swimming-pool air. European Respiratory Journal, 19(5), 827-832.

Uyan, Z. S., Carraro, S., Piacentini, G., \& Baraldi, E. (2009). Swimming pool, respiratory health, and childhood asthma: should we change our beliefs? Pediatric Pulmonology, 44(1), 31-37.

WHO. (2006). Guidelines for safe recreational waters Volume 2-Swimming pools and similar recreationalwater environments. Geneva: World Health Organization.

Wilson, L. D., Zaldivar, F. P., Schwindt, C. D., WangRodriguez, J., \& Cooper, D. M. (2009). Circulating T-regulatory cells, exercise and the elite adolescent swimmer. Pediatr Exerc Sci, 21(3), 305-317. 
Winsley, R., \& Matos, N. (2011). Overtraining and elite young athletes. Medicine and Sport Science, 56, 97105.

Wolfarth, B., Wuestenfeld, J. C., \& Kindermann, W. (2010). Ergogenic effects of inhaled beta2-agonists in nonasthmatic athletes. Endocrinology and Metabolism Clinics of North America, 39(1), 75-87.

Yan, K., Salome, C., \& Woolcock, A. J. (1983). Rapid method for measurement of bronchial responsiveness. Thorax, 38(10), 760-765.

Zang, N., Xie, X., Deng, Y., Wu, S., Wang, L., Peng, C., . . . Liu, E. (2011). Resveratrol-mediated gamma interferon reduction prevents airway inflammation and airway hyperresponsiveness in respiratory syncytial virus-infected immunocompromised mice. Journal of Virology, 85(24), 13061-13068.
Zarzoso, M., Llana, S., \& Pérez-Soriano, P. (2010). Potential negative effects of chlorinated swimming pool attendance on health of swimmers and associated staff. Biology of Sport, 27(4), 233-240.

Zwick, H., Popp, W., Budik, G., Wanke, T., \& Rauscher, H. (1990). Increased sensitization to aeroallergens in competitive swimmers. Lung, 168(2), 111-115.

\section{Correspondence}

Shu-Lin, Lee

Assistant Professor

Address : No. 6, Lane 2, Sec. 3, Shanjiao Rd., Yuanlin Township, Changhua County 510, Taiwan (R.O.C.)

Tel : $\quad+886-939753293$

Fax : +886-4-8359316

E-mail : shulin325@gmail.com 